\title{
Site-specific microinjection of Gaboxadol into the infralimbic cortex modulates ethanol intake in male C57BL/6J mice
}

\author{
Brandon M. Fritz, M.S. and Stephen L. Boehm II, Ph.D. \\ Indiana Alcohol Research Center, Department of Psychology Indiana University - Purdue \\ University Indianapolis, Indiana
}

\section{Abstract}

Extrasynaptic $\mathrm{GABA}_{\mathrm{A}}$ receptors, often identified as those containing both $a 4$ and $\delta$ subunits, demonstrate super-sensitivity to GABA and are involved in tonic inhibitory processes regulating activity within mesolimbocortical circuitry. Rodent studies testing the effects of the $\delta$-subunit selective agonist Gaboxadol (THIP) on alcohol consumption have produced mixed results. The goal of this study was to determine the role of extrasynaptic $\mathrm{GABA}_{\mathrm{A}}$ receptors located in the infralimbic cortex (ILC) in the alcohol consumption of male C57BL/6J (B6) mice. The ILC is of interest due to its demonstrated involvement in stress reactivity. Furthermore, alcohol exposure has been shown to interfere with extinction learning; impairments of which may be related to inflexible behavior (i.e. problematic alcohol consumption). Adult male B6 mice were bilaterally implanted with guide cannulas aimed at the ILC and were subsequently offered daily limited access to $20 \%$ ethanol or 5\% sucrose for 7 days. Immediately prior to ethanol or sucrose access on day 7, mice were bilaterally injected with 50 or $100 \mathrm{ng}$ THIP ( 25 or $50 \mathrm{ng}$ per side respectively) or saline vehicle into the ILC. The highest dose of intra-ILC THIP (100 ng/mouse) increased alcohol intake relative to vehicle controls, although control animals consumed relatively little ethanol following infusion. Intra-ILC THIP had no effect on sucrose consumption $(p>0.05)$, suggesting that the effect of THIP was selective for ethanol consumption. Together, these findings suggest that THIP may have effectively prevented the decrease in ethanol intake on day 7 induced by the microinjection process, perhaps supporting a suggested role for the ILC in adaptive learning processes and behavioral flexibility.

\section{Keywords}

Mouse; Microinjection; Drinking in the Dark; Alcohol; GABA; Gaboxadol; Infralimbic Cortex

\footnotetext{
(C) 2014 Elsevier B.V. All rights reserved.

Corresponding Author: Brandon M. Fritz, Department of Psychology, Indiana University - Purdue University Indianapolis, $402 \mathrm{~N}$ Blackford St, LD 301, Indianapolis, IN 46202, Phone: 952-994-6683, Fax: 317-274-6756, bmfritz@iupui.edu.

Publisher's Disclaimer: This is a PDF file of an unedited manuscript that has been accepted for publication. As a service to our customers we are providing this early version of the manuscript. The manuscript will undergo copyediting, typesetting, and review of the resulting proof before it is published in its final citable form. Please note that during the production process errors may be discovered which could affect the content, and all legal disclaimers that apply to the journal pertain.
} 


\section{Introduction}

Ethanol has been demonstrated potentiate signaling of the primary source of inhibition in the central nervous system, $\gamma$-aminobutyric acid (GABA), through the ionotropic $\mathrm{GABA}_{\mathrm{A}}$ receptor (Mihic et al., 1997, Aguayo, 1990). Pharmacological studies with rodents have demonstrated a role for $\mathrm{GABA}_{\mathrm{A}}$ signaling in voluntary ethanol consumption as well as seeking in operant paradigms via systemic administrations of various $\mathrm{GABA}_{\mathrm{A}}$ receptormodulating drugs, although both promotional and inhibitory effects have been observed (June et al., 1994, Smith et al., 1992, Ramaker et al., 2011, Moore et al., 2007, Boyle et al., 1993, Ramaker et al., 2014). One reason for this may be that the pentameric $\mathrm{GABA}_{\mathrm{A}}$ receptor is a particularly malleable structure, made up of 5 subunits (comprised of various combinations of $a, \beta, \gamma, \delta, \varepsilon, \pi, \rho$ subunits), and is therefore very diverse in both form and function. For example, $\mathrm{GABA}_{\mathrm{A}}$ receptor subtypes containing various forms of the a subunit differentially influence behavioral insensitivity to the sedative hypnotic effects of ethanol and benzodiazepines (Täuber et al., 2003). The significant structural/functional heterogeneity of the $\mathrm{GABA}_{\mathrm{A}}$ receptor suggests that certain isoforms may differentially influence an individual's interactions with ethanol.

The $\mathrm{GABA}_{\mathrm{A}}$ receptor $\delta$ subunit has been of interest in recent years in the ethanol field as some evidence suggests that certain isoforms containing this subunit are particularly sensitive to ethanol at concentrations achievable by environmentally-relevant consumption (as low as 3-30 mM; 15-135 mg/dl)) (Hanchar et al., 2005, Wei et al., 2004, Wallner et al., 2003). However, it is important to note that these studies involved in vitro applications and have not always been replicated (Borghese et al., 2006). Thus far, $\delta$ subunits have been found solely in extrasynaptic regions (Farrant and Nusser, 2005). These putatively extrasynaptic $\mathrm{GABA}_{\mathrm{A}}$ receptors have been demonstrated to produce tonic inhibitory currents and are sensitive to low concentrations of GABA (Hanchar et al., 2005, Mody, 2001). Genetic manipulations of $\delta$ in the rodent brain have demonstrated an important role for this subunit in ethanol-related behavior. A study with $\delta$ subunit knockout mice found that knockouts drink significantly less ethanol in a 2-bottle choice test and display reduced handling-induced convulsions during withdrawal from chronic alcohol treatment relative to wild type mice (Mihalek et al., 2001). Furthermore, region specific knockdown of the $\delta$ subunit in the dorsomedial nucleus accumbens shell via viral-mediated RNAi has also been demonstrated to significantly reduce ethanol intake and preference in rats (Nie et al., 2011). These findings suggest that the $\delta$ subunit is an important factor in ethanol consumption and its influence may even be brain region-specific.

One way to study the role of $\delta$ subunit-containing $\mathrm{GABA}_{\mathrm{A}}$ receptors in ethanol consumption, while keeping them intact, is through pharmacological approaches. Studies suggest that the unique $\mathrm{GABA}_{\mathrm{A}}$ receptor partial agonist, 4,5,6,7-Tetrahydroisoxazolo[5,4c]pyridine-3-ol (THIP or Gaboxadol), is highly selective for $\mathrm{GABA}_{\mathrm{A}}$ receptors containing $\delta$ subunits at particular concentrations (Adkins et al., 2001, Brown et al., 2002, Meera et al., 2011). Our lab has previously shown that systemic administrations of THIP dosedependently reduced the ethanol consumption of C57BL/6J (B6) mice in the 'Drinking-inthe-Dark' paradigm, however this effect was not fluid-specific as water intake was also reduced at the effective doses ( 6 and $8 \mathrm{mg} / \mathrm{kg}$ ) (Moore et al., 2007). Other labs have shown 
both increases (Boyle et al., 1993) and decreases (Ramaker et al., 2011) in voluntary ethanol consumption following THIP administration with various paradigms and THIP has also been shown to alter the appetitive and consummatory processes of operant self-administration (Ramaker et al., 2012). As both $\mathrm{GABA}_{\mathrm{A}}$ receptors and their $\delta$ subunits can be found in numerous brain regions (Fritschy and Mohler, 1995), exploring the effect of locally applied THIP may clarify the role of these receptors in ethanol consumption.

In humans, various regions of the prefrontal cortex (PFC) are the evolutionarily 'highest order' brain regions that have been implicated in problematic drug/alcohol use. The PFC has been particularly implicated in responsivity to drug/alcohol cues and dysfunction in the region is associated with a greater propensity for impulsive action and difficulty maintaining abstinence in heavy users (see Koob and Volkow (2009) for review). As such, disorders of behavioral regulation, such as addiction, may be marked by deficits in PFC function. Imaging studies have found that alcohol-dependent individuals display enhanced alcohol cue reactivity in the dorsolateral (dlPFC) (George et al., 2001) and medial PFC (mPFC) (Grüsser et al., 2004) and that the amount of alcohol consumed in relapse is positively associated with stronger cue reactivity when abstinent (Grüsser et al., 2004). These different regions are functionally and anatomically heterogeneous (Pandya et al., 1996, Petrides and Pandya, 2002) and likely have different roles in drug and alcohol intoxication and dependence. As such, it is important to focus on the unique contributions of PFC subregions to better understand their involvement in responses to alcohol.

The PFC of rodents also has anatomical/functional subdivisions (Vertes, 2004, Sesack et al., 1989 ) and has been demonstrated to play a role in alcohol and drug seeking in operant paradigms (Sun and Rebec, 2005, Van den Oever et al., 2008, Hodge et al., 1996a). The medial PFC (mPFC) can be divided into functionally heterogeneous subregions: the prelimbic cortex (PLC) and the infralimbic cortex (ILC). The PLC has been repeatedly shown to be affected by drug and ethanol exposure and has been heavily implicated in drug and ethanol seeking (Holmes et al., 2012, Kroener et al., 2012, McFarland and Kalivas, 2001, McFarland et al., 2003). Less is known, however, about the role of the ILC in drug and ethanol-related behaviors. Interestingly, it appears to act opposite of the PLC in drug reinforcement. Cocaine seeking is reduced and extinction learning is enhanced when the ILC is stimulated via the glutamate receptor agonist, AMPA (Peters et al., 2008a). Concerning ethanol, lesions of the mPFC (PLC \& ILC) have been shown to impair the extinction of conditioned place preference for ethanol in mice (Groblewski et al., 2012). Chronic intermittent ethanol exposure has also been shown to impair conditioned fear extinction which was attributable to impaired NMDA receptor-mediated burst firing in the ILC (Holmes et al., 2012). Furthermore, chronic intermittent ethanol exposure has been demonstrated to produce deficits in cognitive flexibility (as assessed by a set-shifting task) which the authors suggest may be due to alterations in synaptic plasticity (Kroener et al., 2012). A recent study (Meinhardt et al., 2013) also found that elevated ethanol consumption following chronic intermittent ethanol exposure was associated with reduced expression of the type-2 metabotropic glutamate receptor (mGluR2). When mGluR2 levels were rescued via viral mediated gene transfer, however, ethanol self-administration was greatly reduced. Collectively, these findings demonstrate that ethanol and other drugs of abuse alter glutamatergic signaling in the ILC. There is virtually nothing known, however, about the 
involvement of GABAergic signaling processes in the ILC which may ultimately regulate downstream glutamate signaling. The goal of the current study was to determine the role of putative extrasynaptic $\mathrm{GABA}_{\mathrm{A}}$ receptors located in the ILC in the ethanol intake of B6 mice by employing the DID paradigm and site-specific microinjection of THIP.

\section{Material and Methods}

\subsection{Animals}

Adult (60-100 days old at time of surgery) male B6 mice were either obtained from the Jackson Laboratory (Bar Harbor, ME), or bred on site in our colony at the IUPUI School of Science. The breeders for these in-house animals were originally procured from the Jackson Laboratory and it was ensured that breeding did not take place past two generations from the founder animals. Lighting was maintained on a reverse light-dark cycle with lights off at 0900 , and the temperature and humidity of the room were held constant near $20^{\circ} \mathrm{C}$ and $50 \%$, respectively. All mice were singly housed 7-10 days prior to surgery to allow sufficient time for acclimation to isolate housing. Food and water were available ad libitum, except during the 2-hour drinking access periods where either a $20 \%(\mathrm{v} / \mathrm{v})$ ethanol in tap water solution or a $5 \%(\mathrm{w} / \mathrm{v})$ sucrose in tap water solution was the only fluid available. All experiments were performed under a protocol approved by the IUPUI Institutional Animal Care and Use Committee.

\subsection{Drugs and Drinking Solutions}

The 20\% (v/v) ethanol solution was made by diluting 190 proof ethanol (Pharmco Inc., Brookfield, CT) in tap water. The 5\% (w/v) sucrose solution was prepared by dissolving sucrose (Sigma Aldrich, St. Louis, MO) in tap water. THIP was purchased from Sigma Aldrich (St. Louis, MO) and dissolved in $0.9 \%$ physiological saline vehicle before microinjection.

\subsection{Drinking in the Dark (DID)}

DID takes advantage of the mouse's most active circadian period by providing a limited 2hour ethanol access session during this time (beginning $\sim 3$ hours into the dark cycle). Via the DID paradigm, B6 mice have been shown to drink ethanol to BECs $\geq 80 \mathrm{mg} / \mathrm{dl}$ (Moore et al., 2007, Rhodes et al., 2005), demonstrate motor impairment following ethanol access (Linsenbardt et al., 2011, Rhodes et al., 2007), and develop tolerance following repeated daily drinking bouts (Linsenbardt et al., 2011). Starting $3 \mathrm{hr}$ into the dark cycle each day, animals had their water bottle removed and replaced by a modified $10 \mathrm{ml}$ graduated cylinder drinking tube fitted with a stainless steel double ball bearing sipper (Ancare, Belmore, NY). Animals had daily access to either a $20 \%(\mathrm{v} / \mathrm{v})$ ethanol solution or $5 \%$ sucrose (w/v) solution for 2 hours. During this limited access period, mice did not have access to their regular water bottles. Volume readings were taken immediately before and after the 2 hour access period.

\subsection{Home Cage Locomotor Activity}

Details concerning the exact monitors (Columbus Instruments Inc., Columbus, $\mathrm{OH}$ ) used in the current study were previously published (Linsenbardt and Boehm, 2012). Locomotor 
activity data were collected each day for 2 hours during each DID access period. Home cage activity was monitored to determine whether or not THIP infused into the ILC had a stimulatory or sedative effect which could have competed with the target behavior (drinking).

\subsection{Surgery}

Our stereotaxic surgical procedures have been described elsewhere (Linsenbardt and Boehm II, 2009, Melón and Boehm II, 2011, Moore and Boehm II, 2009). Stainless steel 25-gaugue cannulas were aimed and bilaterally implanted $2 \mathrm{~mm}$ above the ILC via stereotaxic surgery (Model 1900; David Kopf Instruments; Tujunga, CA). Stereotaxic coordinates for the ILC were obtained from the Franklin and Paxinos (1997) mouse brain atlas (from bregma: \pm 0.4 $\mathrm{mm}$ lateral, $+1.685 \mathrm{~mm}$ anterior, $-1.15 \mathrm{~mm}$ ventral). Animals were anesthetized using a ketamine and xylazine cocktail (1\% xylazine/10\% ketamine w/v in saline; i.p.). All mice received an analgesic injection of buprenorphine $(0.03 \mathrm{mg} / \mathrm{kg}$; s.c. $)$ and an antiinflammatory injection of rimadyl $(5 \mathrm{mg} / \mathrm{kg}$; s.c.) immediately following surgery.

\subsection{Blood Ethanol Concentration Determination}

Blood samples $(25 \mu \mathrm{l})$ were spun down in a centrifuge and the plasma was transferred to 0.5 $\mathrm{ml}$ microcentrifuge tubes. Samples were stored at $-80^{\circ} \mathrm{C}$ until determination of BEC in mg/dl by an Analox Alcohol Analyzer (Analox Instruments, Lunenburg, MA).

\subsection{Histology}

Animals were euthanized by $\mathrm{CO}_{2}$ inhalation and brains were extracted and snap frozen in super-cooled 2-methylbutane (Fisher Scientific, Pittsburgh, PA) and stored at $-80^{\circ} \mathrm{C}$ until sectioning. Thirty $\mu \mathrm{m}$ sections were sliced through the ILC using a CM 30505 Leica cryostat (Walldorf, Germany). Tissue was stained with $0.5 \%$ cresyl violet and examined with a Leica dissecting microscope for accurate microinjections. Data from animals that had misplaced cannulas were not included in the analyses. A representative section illustrating accurate bilateral microinjection into the ILC can be seen in Figure 1A. The placements of microinjections for all included animals in the current study can be seen in Figure 1B.

\subsection{Intra-ILC Microinjections}

Our microinjection procedure has been described in detail previously (Linsenbardt and Boehm II, 2009, Melón and Boehm II, 2011, Moore and Boehm II, 2009). On test day (day 7), each animal was restrained, stylets were removed, and microinjectors were slowly inserted $2 \mathrm{~mm}$ past the guide cannulas into the ILC. Infusion rate (382 nl/min) was controlled by a Cole-Parmer (74900-series) dual infusion pump. Microinjectors were left in place for 60 seconds after the infusion had completed to allow time for the fluid to diffuse away from the tips. The microinjectors were then slowly removed to avoid drawing the fluid back up into the cannulas and the animal was placed back into its cage and presented with ethanol or sucrose. 


\subsection{Experiment 1: The effect of intra-ILC THIP on $20 \%$ ethanol intake in DID}

The goal of Experiment 1 was to determine the effect of intra-ILC THIP on ethanol intake and resultant BECs in male B6 mice following a 6-day DID regimen. Mice were habituated to isolated housing for 7-10 days prior to surgery. Mice were bilaterally implanted with cannulas aimed $2 \mathrm{~mm}$ above the ILC and allowed 2 days to recover. Stylets were adjusted during these recovery days to ensure cannula patency. The DID procedure commenced the following day and continued for a total of 7 days. Animals were habituated to the microinjection handling procedure in escalating durations across days 1-6 of DID, immediately prior to ethanol access. Days 1-2 consisted of 30 seconds of restraint and stylet adjustment and restraint duration was increased to 60 seconds on days 3-4. Restraint time on days 5-6 was increased to 90 seconds and included a 'mock microinjection' wherein stylets were removed and microinjectors were slowly inserted only $1 \mathrm{~mm}$ past the guide cannulas. On day 7, animals received bilateral $200 \mathrm{nl}$ infusions of THIP ( 25 or $50 \mathrm{ng} / \mathrm{side}$ or 50 and $100 \mathrm{ng}$ total/mouse, respectively) or saline vehicle. Immediately following ethanol access on day 7 , periorbital blood samples $(25 \mu \mathrm{l})$ were taken for later BEC analysis.

\subsection{Experiment 2}

A separate, naïve cohort of male B6 mice was used in Experiment 2. The work was carried out identically to Experiment 1, except animals were presented with a $5 \%$ (w/v) sucrose solution during the DID access periods. The effect of intra-ILC THIP on sucrose intake was evaluated to determine whether the observed effect on ethanol intake was specific to ethanol itself or whether it generalized to an alternate reinforcer.

\subsection{Statistical Analysis}

Only animals with confirmed bilateral microinjection into the ILC were included in the analyses. Out of a total of 84 mice implanted, 4 mice (3 ethanol and 1 sucrose) lost their skullcaps during the habituation phase, and 8 mice were excluded due to very low ethanol intake throughout the habituation phase $(<2 \mathrm{~g} / \mathrm{kg}$ daily average over days $1-6)$. Of the 70 mice that met ethanol consumption criteria ( $\geq 2 \mathrm{~g} / \mathrm{kg}$ day $1-6$ average), 53 were confirmed bilateral hits which translates to surgical accuracy of $75.7 \%$. For both experiments, fluid intake and home cage locomotor activity across the 6 microinjection habituation days were analyzed by two-way, repeated measures ANOVAs using subsequent dose group and day as factors. Fluid intake (Experiments $1 \& 2$ ) and BEC (Experiment 1) following access on day 7 were analyzed by one-way ANOVAs with dose group as the factor for both experiments. Total ambulatory activity during the test day was also analyzed via one-way ANOVAs with group as the factor in both experiments. Newman-Keuls post-hoc tests were conducted where applicable and the level of significance was set at $p<0.05$. All analyses were carried out using Statistica 7 software (StatSoft, Tulsa, OK).

\section{Results}

\subsection{Experiment 1: The effect of intra-ILC THIP on $20 \%(\mathrm{v} / \mathrm{v})$ ethanol intake in DID}

The acquisition of $20 \%$ ethanol consumption across the 6-days of handling exposure and DID acquisition is presented in Figure 2A. These data are presented collapsed on subsequent drug dose group as ethanol consumption between groups was not significantly different 
$\left(F_{2,26}=1.47, p=0.248\right)$. Furthermore, the potential interaction between subsequent dose group and day was not significant $\left(F_{10,130}=0.879 ; p=0.555\right)$. As such, any differences in ethanol consumption between groups following microinfusion can be attributed to the dose of THIP and not differences in baseline ethanol consumption. To assess the degree to which the increasing handling durations and 'mock microinjections' influenced ethanol intake over the course of the acquisition phase for all mice, the significant main effect of day $\left(F_{5,130}=\right.$ $4.021, p<0.01)$ was followed up with post-hoc testing, revealing that intake on day 5 following the first 'mock microinjection' was significantly lower than intake on days 3 and 4 ( $p$ < 0.05). Ethanol intake was deemed to have recovered on day 6 following the second 'mock microinjection' as intake on this day was not significantly different from any other days $(p>0.05)$. The subsequent THIP dose groups were also not found to significantly differ in home cage locomotor activity across the 6 habituation days $\left(F_{2,26}=0.091, p=\right.$ $0.913)$. However, a main effect of day $\left(F_{5,130}=7.419, p<0.001\right)$ indicated that activity on days 5 and 6 was significantly reduced relative to days $1-4$ ( $p$ 's $<0.05$; Figure $2 \mathrm{~B}$ ).

Following microinfusion on day 7 , a main effect of dose was found $\left(F_{2,26}=5.144, p<0.05\right)$ with the $100 \mathrm{ng}$ dose group consuming significantly more ethanol than the vehicle controls ( $p<0.05$; Figure 3A). The analysis of BECs following DID access on day 7 revealed a main effect of dose $\left(F_{2,26}=12.333, p<0.001\right)$ with the $100 \mathrm{ng}$ THIP dose group reaching significantly higher BECs than the vehicle and $50 \mathrm{ng}$ THIP dose groups ( $p$ 's $<0.05$; Figure $3 \mathrm{~B})$. Home cage locomotor activity following microinfusion was not significantly different between groups $\left(F_{2,26}=1.647, p=0.212\right.$; Figure $\left.3 \mathrm{C}\right)$.

\subsection{Experiment 2: The effect of intra-ILC THIP on $5 \%(\mathrm{v} / \mathrm{v})$ sucrose intake in DID}

The acquisition of 5\% sucrose consumption across the 6-days of handling exposure and DID is presented in Figure 4A. Sucrose consumption between subsequent THIP dose groups was not significantly different $\left(F_{2,19}=0.321, p=0.73\right)$ and these data are therefore presented collapsed on group. A main effect of day was found $\left(F_{5,95}=8.696, p<0.001\right)$ with intake on day 5 following the first 'mock microinjection' being significantly lower than intake on days 3 and 4 ( $p<0.05)$. Sucrose intake also recovered on day 6 following the second 'mock microinjection' as intake on this day was not significantly different from any other days $(p>$ 0.05). The subsequent THIP dose groups were also not found to significantly differ in home cage locomotor activity across the 6 habituation days $\left(F_{2,19}=1.045, p=0.371\right.$; Figure $\left.4 \mathrm{~B}\right)$. However, an overall main effect of day $\left(F_{5,95}=4.63, p<0.001\right)$ indicated that activity on day 5 following the first mock microinjection was significantly lower than days 1-4 and activity on day 6 was significantly lower than days $2-3$ ( $p$ 's $<0.05)$.

Following microinfusion on day 7, THIP was found to have no effect on sucrose consumption $\left(F_{2,19}=0.606, p=0.556\right.$; Figure $\left.5 \mathrm{~A}\right)$. Home cage locomotor activity following microinfusion was also not significantly different between groups $\left(F_{2,19}=1.458, p=0.257\right.$; Figure 5B).

\section{Discussion}

The current study found that THIP (100 ng) locally applied to the ILC produced greater ethanol consumption compared to vehicle. However, this 'increase' was relative to a 
substantial decrease in vehicle mice. Furthermore, this effect appeared to be ethanol-specific as sucrose consumption was not affected by THIP. These observations are in contrast with previous systemic work with THIP and DID in our lab (Moore et al., 2007) and suggest a role for $\mathrm{GABA}_{\mathrm{A}}$ receptors in the ILC in the positive modulation of ethanol consumption.

Previous work evaluating the role of mesolimbocortical $\mathrm{GABA}_{\mathrm{A}}$ receptors in rodent ethanol consumption has offered valuable insight on region-specific $\mathrm{GABA}_{\mathrm{A}}$ receptor signaling. Infusion of the $\mathrm{GABA}_{\mathrm{A}}$ agonist, muscimol, into the VTA was observed to have no effect on operant responding for ethanol in rats (Hodge et al., 1996b), although infusion into the mPFC reduced ethanol intake (Samson and Chappell, 2001). Other studies demonstrated that $\mathrm{GABA}_{\mathrm{A}}$ antagonism in both the anterior region of the VTA (Nowak et al., 1998) and extended amygdala (Hyytiä and Koob, 1995) reduced ethanol intake. Whether or not $\delta$ subunit-containing receptors are partly responsible for such effects is not known and to our knowledge, no published studies currently exist that explore region-specific effects of THIP on ethanol intake. Studies employing systemic administration methods have found evidence for both increased (Boyle et al., 1993, Boyle et al., 1992) and decreased (Moore et al., 2007, Ramaker et al., 2011, Ramaker et al., 2012) ethanol consumption following THIP. Potential reasons for this discrepancy may be due to the use of different species (rats vs. mice), different ethanol access schedules, different drinking paradigms (2-bottle choice vs. single bottle), different ethanol concentrations, or timing of drug administration. It is also important to note that moderate/high systemic doses of THIP $(4-16 \mathrm{mg} / \mathrm{kg})$ have been observed to have non-specific effects on fluid intake with observations of such doses reducing water or sucrose intake (Moore et al., 2007, Ramaker et al., 2012), potentially reflective of sedative effects. It is therefore important to carefully consider dosage when exploring ethanol drinking-specific effects of THIP.

In the present study, mice that received the $100 \mathrm{ng}$ dose of intra-ILC THIP consumed significantly more ethanol than the saline vehicle group (Figure 3A) and attained significantly higher BECs than both the vehicle and $50 \mathrm{ng}$ THIP dose groups (Figure 3B). However, it is important to note that the vehicle group on day 7 displayed a large reduction in ethanol consumption relative to day 6 , and the day 7 intake of the $100 \mathrm{ng}$ group was nearly equivalent to the universal average on day 6 (Figures $2 \mathrm{~A}$ and $3 \mathrm{~A}$ ). A paired t-test comparing baseline ethanol intake for animals assigned to the vehicle group on day 6 to the intake on day 7 trended towards significance $(t(8)=2.258, p=0.054)$, suggesting that ethanol intake in this group was perturbed. Interestingly, this decrease in intake from day 6 to day 7 was not observed in the sucrose-consuming vehicle group (Figures $4 \mathrm{~A}$ and $5 \mathrm{~A}$ ). Perhaps one interpretation of this observation is that the animals that consumed ethanol may have had particularly negative reactions to the microinfusion process.

The microinjection process is unquestionably stressful as the animals are restrained for a considerable period of time ( $~ 90$ seconds) and have microinjectors inserted into their brain. A role for the ILC in extinction learning (Milad and Quirk, 2002), behavioral flexibility (Kroener et al., 2012), and drug seeking (Peters et al., 2008a) has been demonstrated and chronic intermittent ethanol exposure can produce neurophysiological abnormalities in the ILC associated with these forms of maladaptive learning (Holmes et al., 2012, Kroener et al., 2012). As an acute uncontrollable stressor has been shown to produce similar alterations 
in the ILC (Izquierdo et al., 2006), it may therefore be that handling stress, in conjunction with ethanol exposure, in the present study was sufficient to induce functional changes in the ILC which made these mice particularly reactive to the microinfusion process on day 7 .

Although the microinfusion itself may have decreased ethanol intake in vehicle control animals, interestingly, the $100 \mathrm{ng}$ dose of intra-ILC THIP prevented this large decrease in consumption. We are hesitant to say that THIP increased ethanol intake as the intake of the $100 \mathrm{ng}$ dose group was similar to intake on day 6 (Figures 2A and 3A). Rather, it appears that the highest dose of THIP may have mitigated the negative response to the microinfusion process in the ethanol animals. Perhaps the simplest interpretation of this finding is that the infusion $100 \mathrm{ng}$ THIP into the ILC was somehow anxiolytic. The ILC has been demonstrated to provide indirect inhibition of the central nucleus of the amygdala (Quirk et al., 2003) and some evidence suggests this occurs via excitatory glutamatergic input to GABAergic intercalated amygdala neurons which then provide inhibitory input to the central nucleus (Berretta et al., 2005). Perhaps intra-ILC THIP disinhibited these glutamatergic efferents via inhibition of local GABAergic interneurons and promoted anxiolysis in the current study.

Another possibility is that THIP may have altered adaptive learning processes governed by the ILC. Existing research has mostly focused on the role of the ILC in drug and ethanol extinction learning or seeking in animals that either are dependent or have had extensive drug experience (Meinhardt et al., 2013, Ovari and Leri, 2008, Peters et al., 2008a, Peters et al., 2008b). Collectively, these studies predominantly suggest that increased activity in the ILC is associated with enhanced extinction learning and reduced drug and ethanol seeking. The mice used in the current study were non-dependent and little is known about the involvement of the ILC in ethanol-related behaviors in non-dependent animals. A recent study suggested that the ILC may be involved in processing contextual cues associated with ethanol intoxication in pre-dependent animals (Groblewski et al., 2012). The experimental procedure of the current study provides many contextual cues (e.g. handling, experimenter odor, ethanol odor) which may be associated with access to ethanol and/or intoxication which could have facilitated neurobiological changes in the ILC. In conjunction with observations that perturbations of the ILC are associated with disrupted cognitive flexibility (Kroener et al., 2012) and impulsivity (Chudasama et al., 2003), dysfunction in the ILC may generally manifest as cognitive-behavioral inflexibility. In other words, it is convincing that the ILC is an important hub for the incorporation of relevant contextual information to influence subsequent behavior in an adaptive fashion.

It is tempting to speculate that a possible mechanism whereby THIP may have interfered with adaptive learning processes in the ILC, effectively preventing a decrease in ethanol intake, may have been a region-specific decrease in excitatory glutamatergic output to the nucleus accumbens shell (NAcbSh). Previous research has demonstrated that glutamatergic projections from the ILC to the NAcbSh are necessary to maintain the extinction of operant responding for cocaine (Peters et al., 2008a). These excitatory projections synapse onto inhibitory GABAergic neurons in the NAcbSh which then project to the ventral pallidum, which may ultimately inhibit drug seeking (McFarland and Kalivas, 2001). It has also been observed that blocking AMPA and kainate glutamate receptors in the NAcbSh produces a 
robust increase in feeding behavior (Maldonado-Irizarry et al., 1995). Therefore, glutamatergic input to the NAcbSh may be an important mechanism by which the ILC regulates hedonic behaviors. Perhaps enhancing GABAergic regulation of these excitatory glutamate efferents in the ILC via THIP ultimately prevented a decrease in ethanol consumption following microinfusion via a reduction in inhibitory drive to the ventral pallidum.

To evaluate whether or not THIP may have prevented a decrease in behavioral activation brought on by the microinfusion process in general, a follow-up analysis of home cage locomotor activity of all mice (analysis collapsed on ethanol and sucrose consumption) on day 7 was conducted. Interestingly, there was a main effect of dose $\left(F_{2,48}=3.881, p=\right.$ 0.027 ) with animals receiving the $100 \mathrm{ng}$ THIP dose being significantly more active than saline vehicle controls $(\mathrm{p}<0.05)$. When carefully examining these data, it again appears that THIP may have prevented a decrease from baseline activity that was observed in the saline controls. As can be seen in Figures $3 \mathrm{C}$ and 5B, the vehicle groups exhibit the least activity on test day and the $100 \mathrm{ng}$ THIP dose groups appear unaltered from baseline on day 6 .

Taken together with the drinking data (Figures 3A and 5A), it appears that there may have been an inhibitory effect of the microinfusion process that the $100 \mathrm{ng}$ THIP dose effectively prevented, supporting the hypothesis above. However, no decrease in consumption on day 7 was observed in the vehicle group that consumed sucrose (Figure 5A). Therefore, the amount of fluid consumption, in general, does not appear to be directly related to locomotor activity across these two experiments and the effect of THIP on ethanol intake may therefore not necessarily be related to a general effect of the compound on activity. It is possible that among ethanol-consuming mice, the greater amount of ethanol consumed in the $100 \mathrm{ng}$ dose group may have influenced the observation of higher activity, not necessarily a THIPinduced increase in activity. Based on the main effect of dose in the overall analysis above, however, it is difficult to disentangle these possibilities.

In conclusion, these findings contrast with the previous observation of systemic THIP to reduce ethanol intake in the DID paradigm in our lab (Moore et al., 2007), demonstrating that locally applied THIP in the ILC elevated ethanol consumption relative to saline controls. Furthermore, intra-ILC THIP was not found to influence sucrose intake nor did it have concrete effects on locomotor activity, suggesting that the doses used here were specific for ethanol intake. The $\delta$ subunit of the $\mathrm{GABA}_{\mathrm{A}}$ receptor is indeed present in the rodent ILC (Fritschy and Mohler, 1995), offering opportunity for selective activation of extrasynaptic receptors. However, the cell-type distribution of the $\mathrm{GABA}_{\mathrm{A}}$ receptor $\delta$ subunit in the ILC is not known and it will be important to determine whether or not putative extrasynaptic receptor subtypes containing this subunit are present in particular projection neurons or possibly regulatory interneurons. Furthermore, it has been previously shown that the local concentration of GABA and density of extrasynaptic receptors can influence the potency of THIP to promote tonic inhibition in cerebellar granule cells with GABA concentrations $>10 \mu \mathrm{M}$ blunting this effect (Houston et al., 2012). Evaluations of local GABA levels in the rodent ILC will therefore offer clarity on whether THIP was likely acting at synaptic or extrasynaptic receptors in the current study. Nevertheless, intra-ILC THIP was found to prevent the reduced ethanol (but not sucrose) intake observed in 
conjunction with our microinjection procedures, suggesting that the activation of $\delta$-subunitcontaining $\mathrm{GABA}_{\mathrm{A}}$ receptors in the ILC can influence ethanol intake. Future studies should address the synaptic versus extrasynaptic receptor question by employing synaptic $\mathrm{GABA}_{\mathrm{A}}$ receptor agonists.

\section{Acknowledgments}

This work was supported by grants AA016789 (SB) and AA07462 (BF) from the NIAAA.

\section{References}

Adkins CE, Pillai GV, Kerby J, Bonnert TP, Haldon C, Mckernan RM, Gonzalez JE, Oades K, Whiting PJ, Simpson PB. a $4 \beta 3 \delta \mathrm{GABA}_{\mathrm{A}}$ receptors characterized by fluorescence resonance energy transfer-derived measurements of membrane potential. Journal of Biological Chemistry. 2001; 276:38934-38939. [PubMed: 11495904]

Aguayo LG. Ethanol potentiates the $\mathrm{GABA}_{\mathrm{A}}$-activated $\mathrm{Cl}^{-}$current in mouse hippocampal and cortical neurons. European journal of pharmacology. 1990; 187:127-130. [PubMed: 1703076]

Berretta S, Pantazopoulos H, Caldera M, Pantazopoulos P, Paré D. Infralimbic cortex activation increases c-fos expression in intercalated neurons of the amygdala. Neuroscience. 2005; 132:943953. [PubMed: 15857700]

Borghese CM, Stórustovu SÍ, Ebert B, Herd MB, Belelli D, Lambert JJ, Marshall G, Wafford KA, Harris RA. The $\delta$ Subunit of $\gamma$-Aminobutyric Acid Type A Receptors Does Not Confer Sensitivity to Low Concentrations of Ethanol. Journal of Pharmacology and Experimental Therapeutics. 2006; 316:1360-1368. [PubMed: 16272217]

Boyle AE, Segal R, Smith BR, Amit Z. Bidirectional effects of GABAergic agonists and antagonists on maintenance of voluntary ethanol intake in rats. Pharmacology Biochemistry and Behavior. 1993; 46:179-182.

Boyle AE, Smith BR, Amit Z. Microstructural analysis of the effects of THIP, a GABAA agonist, on voluntary ethanol intake in laboratory rats. Pharmacology Biochemistry and Behavior. 1992; 43:1121-1127.

Brown N, Kerby J, Bonnert TP, Whiting PJ, Wafford KA. Pharmacological characterization of a novel cell line expressing human a $4 \beta 3 \delta \mathrm{GABA}_{\mathrm{A}}$ receptors. British Journal of Pharmacology. 2002; 136:965. [PubMed: 12145096]

Chudasama Y, Passetti F, Rhodes SEV, Lopian D, Desai A, Robbins TW. Dissociable aspects of performance on the 5-choice serial reaction time task following lesions of the dorsal anterior cingulate, infralimbic and orbitofrontal cortex in the rat: differential effects on selectivity, impulsivity and compulsivity. Behavioural Brain Research. 2003; 146:105-119. [PubMed: 14643464]

Farrant M, Nusser Z. Variations on an inhibitory theme: phasic and tonic activation of GABAA receptors. Nat Rev Neurosci. 2005; 6:215-229. [PubMed: 15738957]

Franklin, K.; Paxinos, G. The mouse brain in stereotaxic coordinates. Academic Press; San Diego: 1997.

Fritschy J-M, Mohler H. GABAA-receptor heterogeneity in the adult rat brain: Differential regional and cellular distribution of seven major subunits. The Journal of Comparative Neurology. 1995; 359:154-194. [PubMed: 8557845]

George MS, Anton RF, Bloomer C, Teneback C, Drobes DJ, Lorberbaum JP, Nahas Z, Vincent DJ. Activation of prefrontal cortex and anterior thalamus in alcoholic subjects on exposure to alcoholspecific cues. Archives of General Psychiatry. 2001; 58:345-352. [PubMed: 11296095]

Groblewski PA, Ryabinin AE, Cunningham CL. Activation and role of the medial prefrontal cortex (mPFC) in extinction of ethanol-induced associative learning in mice. Neurobiology of Learning and Memory. 2012; 97:37-46. [PubMed: 21951632]

Grüsser S, Wrase J, Klein S, Hermann D, Smolka M, Ruf M, Weber-Fahr W, Flor H, Mann K, Braus D, Heinz A. Cue-induced activation of the striatum and medial prefrontal cortex is associated with 
subsequent relapse in abstinent alcoholics. Psychopharmacology. 2004; 175:296-302. [PubMed: 15127179]

Hanchar HJ, Dodson PD, Olsen RW, Otis TS, Wallner M. Alcohol-induced motor impairment caused by increased extrasynaptic GABA $_{A}$ receptor activity. Nat Neurosci. 2005; 8:339-345. [PubMed: 15696164]

Hodge CW, Chappelle AM, Samson HH. Dopamine receptors in the medial prefrontal cortex influence ethanol and sucrose-reinforced responding. Alcoholism: Clinical and Experimental Research. 1996a; 20:1631-1638.

Hodge CW, Haraguchi M, Chappelle AM, Samson HH. Effects of Ventral Tegmental Microinjections of the GABAA Agonist Muscimol on Self-Administration of Ethanol and Sucrose. Pharmacology Biochemistry and Behavior. 1996b; 53:971-977.

Holmes A, Fitzgerald PJ, Macpherson KP, Debrouse L, Colacicco G, Flynn SM, Masneuf S, Pleil KE, Li C, Marcinkiewcz CA, Kash TL, Gunduz-Cinar O, Camp M. Chronic alcohol remodels prefrontal neurons and disrupts NMDAR-mediated fear extinction encoding. Nat Neurosci. 2012; 15:1359-1361. [PubMed: 22941108]

Houston CM, Mcgee TP, Mackenzie G, Troyano-Cuturi K, Rodriguez PM, Kutsarova E, Diamanti E, Hosie AM, Franks NP, Brickley SG. Are extrasynaptic GABAA receptors important targets for sedative/hypnotic drugs? The Journal of Neuroscience. 2012; 32:3887-3897. [PubMed: 22423109]

Hyytiä P, Koob GF. GABAA receptor antagonism in the extended amygdala decreases ethanol selfadministration in rats. European Journal of Pharmacology. 1995; 283:151-159. [PubMed: 7498304]

Izquierdo A, Wellman CL, Holmes A. Brief uncontrollable stress causes dendritic retraction in infralimbic cortex and resistance to fear extinction in mice. The Journal of Neuroscience. 2006; 26:5733-5738. [PubMed: 16723530]

June HL, Murphy JM, Mellor-Burke JJ, Lumeng L, Li T-K. The benzodiazepine inverse agonist RO19-4603 exerts prolonged and selective suppression of ethanol intake in alcohol-preferring (P) rats. Psychopharmacology. 1994; 115:325-331. [PubMed: 7871072]

Koob GF, Volkow ND. Neurocircuitry of addiction. Neuropsychopharmacology. 2009; 35:217-238. [PubMed: 19710631]

Kroener S, Mulholland PJ, New NN, Gass JT, Becker HC, Chandler LJ. Chronic alcohol exposure alters behavioral and synaptic plasticity of the rodent prefrontal cortex. PLoS ONE. 2012; 7:e37541. [PubMed: 22666364]

Linsenbardt DN, Boehm SL II. Agonism of the endocannabinoid system modulates binge-like alcohol intake in male C57BL/6J mice: involvement of the posterior ventral tegmental area. Neuroscience. 2009; 164:424-434. [PubMed: 19665522]

Linsenbardt DN, Boehm SL. Role of novelty and ethanol history in locomotor stimulation induced by binge-like ethanol intake. Alcoholism: Clinical and Experimental Research. 2012; 36:887-894.

Linsenbardt DN, Moore EM, Griffin KD, Gigante ED, Boehm SL 2nd. Tolerance to ethanol's ataxic effects and alterations in ethanol-induced locomotion following repeated binge-like ethanol intake using the DID model. Alcoholism: Clinical and Experimental Research. 2011; 35:1246-1255.

Maldonado-Irizarry C, Swanson C, Kelley A. Glutamate receptors in the nucleus accumbens shell control feeding behavior via the lateral hypothalamus. The Journal of Neuroscience. 1995; 15:6779-6788. [PubMed: 7472436]

Mcfarland K, Kalivas PW. The circuitry mediating cocaine-induced reinstatement of drug-seeking behavior. The Journal of Neuroscience. 2001; 21:8655-8663. [PubMed: 11606653]

Mcfarland K, Lapish CC, Kalivas PW. Prefrontal glutamate release into the core of the nucleus accumbens mediates cocaine-induced reinstatement of drug-seeking behavior. The Journal of Neuroscience. 2003; 23:3531-3537. [PubMed: 12716962]

Meera P, Wallner M, Otis TS. Molecular basis for the high THIP/gaboxadol sensitivity of

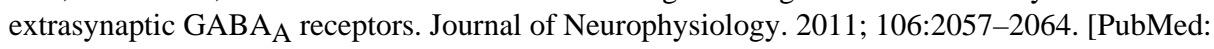
21795619]

Meinhardt MW, Hansson AC, Perreau-Lenz S, Bauder-Wenz C, Stählin O, Heilig M, Harper C, Drescher KU, Spanagel R, Sommer WH. Rescue of infralimbic mGluR2 deficit restores control 
over drug-seeking behavior in alcohol dependence. The Journal of Neuroscience. 2013; 33:27942806. [PubMed: 23407939]

Melón LC, Boehm SL II. GABA A receptors in the posterior, but not anterior, ventral tegmental area mediate Ro15-4513-induced attenuation of binge-like ethanol consumption in C57BL/6J female mice. Behavioural brain research. 2011; 220:230-237. [PubMed: 21320533]

Mihalek RM, Bowers BJ, Wehner JM, Kralic JE, Vandoren MJ, Morrow AL, Homanics GE. GABAAReceptor $\delta$ Subunit Knockout Mice Have Multiple Defects in Behavioral Responses to Ethanol. Alcoholism: Clinical AND Experimental Research. 2001; 25:1708-1718.

Mihic SJ, Ye Q, Wick MJ, Koltchine VV, Krasowski MD, Finn SE, Mascia MP, Valenzuela CF, Hanson KK, Greenblatt EP. Sites of alcohol and volatile anaesthetic action on GABAA and glycine receptors. Nature. 1997; 389:385-389. [PubMed: 9311780]

Milad MR, Quirk GJ. Neurons in medial prefrontal cortex signal memory for fear extinction. Nature. 2002; 420:70-74. [PubMed: 12422216]

Mody I. Distinguishing between GABAA receptors responsible for tonic and phasic conductances. Neurochemical research. 2001; 26:907-913. [PubMed: 11699942]

Moore EM, Boehm SL II. Site-specific microinjection of baclofen into the anterior ventral tegmental area reduces binge-like ethanol intake in male C57BL/6J mice. Behavioral neuroscience. 2009; 123:555. [PubMed: 19485562]

Moore EM, Serio KM, Goldfarb KJ, Stepanovska S, Linsenbardt DN, Boehm SL II. GABAergic modulation of binge-like ethanol intake in C57BL/6J mice. Pharmacology Biochemistry and Behavior. 2007; 88:105-113.

Nie H, Rewal M, Gill TM, Ron D, Janak PH. Extrasynaptic $\delta$-containing GABAA receptors in the nucleus accumbens dorsomedial shell contribute to alcohol intake. Proceedings of the National Academy of Sciences. 2011; 108:4459-4464.

Nowak KL, Mcbride WJ, Lumeng L, Li TK, Murphy JM. Blocking GABAA receptors in the anterior ventral tegmental area attenuates ethanol intake of the alcohol-preferring $\mathrm{P}$ rat. Psychopharmacology. 1998; 139:108-116. [PubMed: 9768548]

Ovari J, Leri F. Inactivation of the ventromedial prefrontal cortex mimics re-emergence of heroin seeking caused by heroin reconditioning. Neuroscience Letters. 2008; 444:52-55. [PubMed: 18706971]

Pandya DN, Yeterian EH, Fleminger S, Dunnett SB. Comparison of prefrontal architecture and connections [and Discussion]. Philosophical Transactions of the Royal Society of London Series B: Biological Sciences. 1996; 351:1423-1432.

Peters J, Lalumiere RT, Kalivas PW. Infralimbic prefrontal cortex Is responsible for inhibiting cocaine seeking in extinguished rats. The Journal of Neuroscience. 2008a; 28:6046-6053. [PubMed: 18524910]

Peters J, Vallone J, Laurendi K, Kalivas P. Opposing roles for the ventral prefrontal cortex and the basolateral amygdala on the spontaneous recovery of cocaine-seeking in rats. Psychopharmacology. 2008b; 197:319-326. [PubMed: 18066533]

Petrides M, Pandya DN. Comparative cytoarchitectonic analysis of the human and the macaque ventrolateral prefrontal cortex and corticocortical connection patterns in the monkey. European Journal of Neuroscience. 2002; 16:291-310. [PubMed: 12169111]

Quirk GJ, Likhtik E, Pelletier JG, Paré D. Stimulation of medial prefrontal cortex decreases the responsiveness of central amygdala output neurons. The Journal of Neuroscience. 2003; 23:8800 8807. [PubMed: 14507980]

Ramaker M, Ford M, Phillips T, Finn D. Differences in the reinstatement of ethanol seeking with ganaxolone and gaboxadol. Neuroscience. 2014; 272:180-187. [PubMed: 24814021]

Ramaker MJ, Ford MM, Fretwell AM, Finn DA. Alteration of ethanol drinking in mice via modulation of the $\mathrm{GABA}_{\mathrm{A}}$ receptor with ganaxolone, finasteride, and gaboxadol. Alcoholism: Clinical and Experimental Research. 2011; 35:1994-2007.

Ramaker MJ, Strong MN, Ford MM, Finn DA. Effect of ganaxolone and THIP on operant and limitedaccess ethanol self-administration. Neuropharmacology. 2012; 63:555-564. [PubMed: 22613838] 
Rhodes JS, Best K, Belknap JK, Finn DA, Crabbe JC. Evaluation of a simple model of ethanol drinking to intoxication in C57BL/6J mice. Physiology \& Behavior. 2005; 84:53-63. [PubMed: 15642607]

Rhodes JS, Ford MM, Yu CH, Brown LL, Finn DA, Garland T, Crabbe JC. Mouse inbred strain differences in ethanol drinking to intoxication. Genes, Brain and Behavior. 2007; 6:1-18.

Samson HH, Chappell A. Muscimol injected into the medial prefrontal cortex of the rat alters ethanol self-administration. Physiology \& behavior. 2001; 74:581-587. [PubMed: 11790418]

Sesack SR, Deutch AY, Roth RH, Bunney BS. Topographical organization of the efferent projections of the medial prefrontal cortex in the rat: An anterograde tract-tracing study with Phaseolus vulgaris leucoagglutinin. The Journal of Comparative Neurology. 1989; 290:213-242. [PubMed: 2592611]

Smith BR, Robidoux J, Amit Z. GABAergic involvement in the acquisition of voluntary ethanol intake in laboratory rats. Alcohol and Alcoholism. 1992; 27:227-231. [PubMed: 1333211]

Sun W, Rebec G. The role of prefrontal cortex D1-like and D2-like receptors in cocaine-seeking behavior in rats. Psychopharmacology. 2005; 177:315-323. [PubMed: 15309375]

Täuber M, Calame-Droz E, Prut L, Rudolph U, Crestani F. a2- $\gamma$-aminobutyric acid (GABA)A receptors are the molecular substrates mediating precipitation of narcosis but not of sedation by the combined use of diazepam and alcohol in vivo. European Journal of Neuroscience. 2003; 18:2599-2604. [PubMed: 14622161]

Van Den Oever MC, Goriounova NA, Wan Li K, Van Der Schors RC, Binnekade R, Schoffelmeer ANM, Mansvelder HD, Smit AB, Spijker S, De Vries TJ. Prefrontal cortex AMPA receptor plasticity is crucial for cue-induced relapse to heroin-seeking. Nat Neurosci. 2008; 11:1053-1058. [PubMed: 19160503]

Vertes RP. Differential projections of the infralimbic and prelimbic cortex in the rat. Synapse. 2004; 51:32-58. [PubMed: 14579424]

Wallner M, Hanchar HJ, Olsen RW. Ethanol enhances a $4 \beta 3 \delta$ and $\alpha 6 \beta 3 \delta \gamma$-aminobutyric acid type A receptors at low concentrations known to affect humans. Proceedings of the National Academy of Sciences. 2003; 100:15218-15223.

Wei W, Faria LC, Mody I. Low ethanol concentrations selectively augment the tonic inhibition mediated by $\delta$ subunit-containing $\mathrm{GABA}_{\mathrm{A}}$ receptors in hippocampal neurons. The Journal of Neuroscience. 2004; 24:8379-8382. [PubMed: 15385620] 


\section{Highlights}

- We explore the role of GABA in the infralimbic cortex (ILC) on binge-like alcohol drinking in mice

- Bilateral microinfusion of the delta-subunit selective $\mathrm{GABA}_{\mathrm{A}}$ agonist gaboxadol increased alcohol intake

- This effect was not observed with sucrose consumption and was therefore ethanol-specific

- Ethanol-intake-specific effect was not due to motor effects of the drug 
A

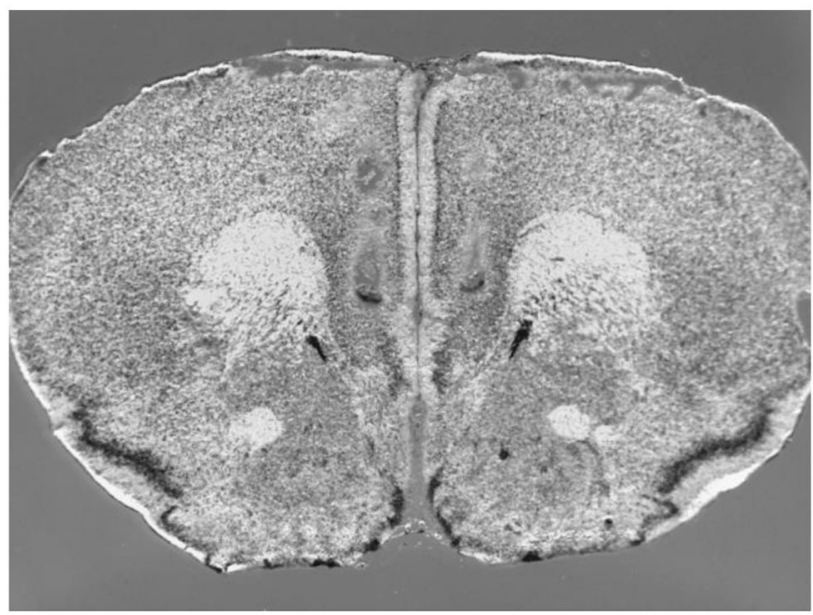

B

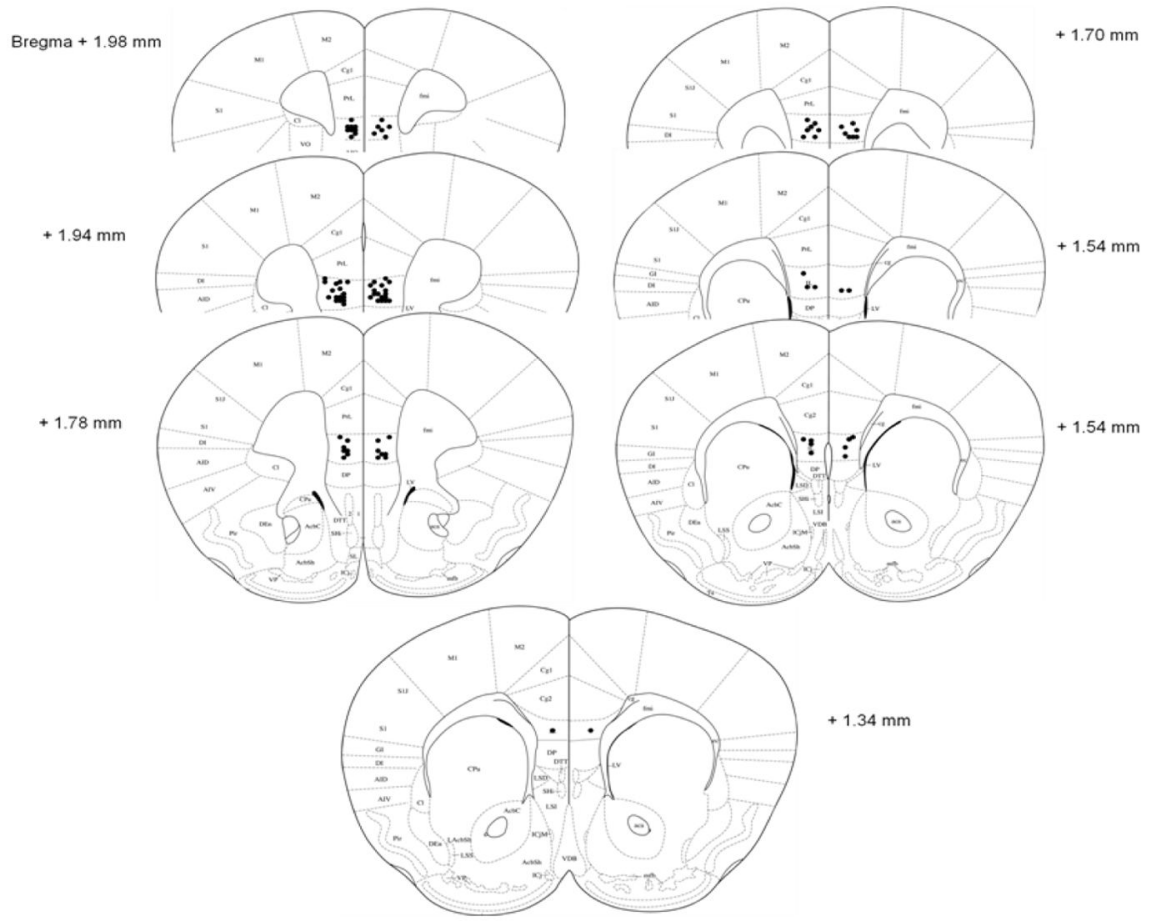

Figure 1. Representation of surgical accuracy

A) Representative cresyl violet-stained section depicting bilateral insertion of microinjection cannulas into the ILC. B) Stereotaxic map illustrating the microinjection sites for all animals included in the analyses. 


\section{A $20 \%$ Ethanol Consumption}

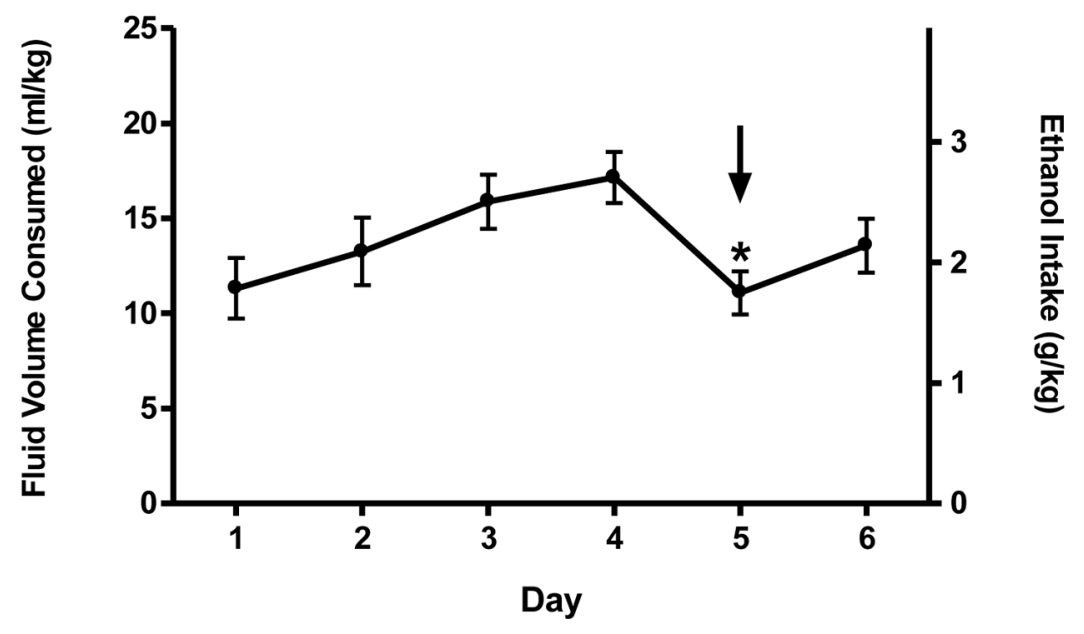

B Home Cage Locomotor Activity - Ethanol

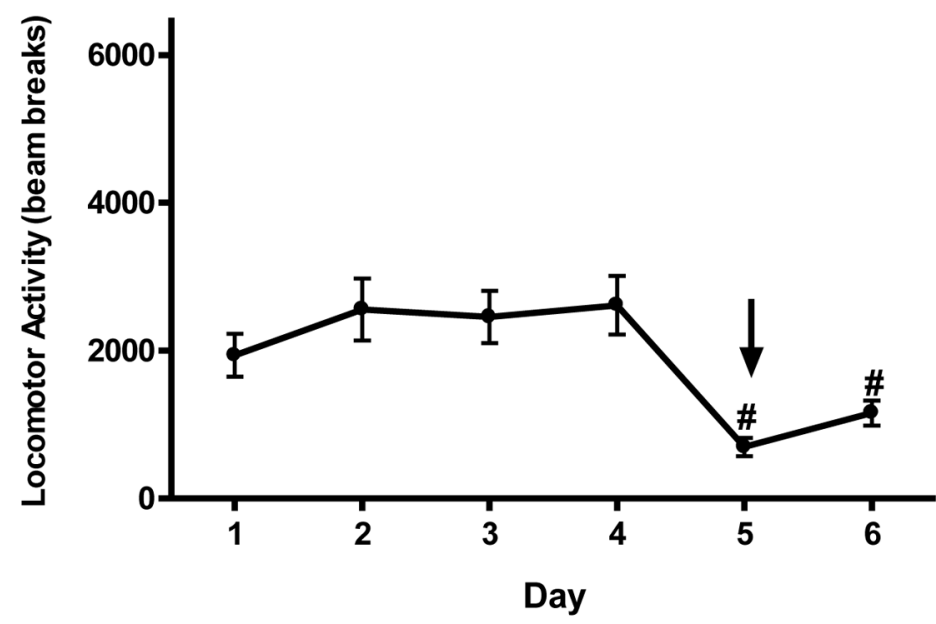

Figure 2. Acquisition of ethanol drinking

A) Consumption of $20 \%(\mathrm{v} / \mathrm{v})$ ethanol via DID and B) home cage locomotor activity across the 6 days of handling habituation. The data are presented collapsed on subsequent THIP dose group as there were no significant differences $(p>0.05)$ between groups in ethanol intake or activity across days $1-6(\mathrm{~N}=31)$. The arrow notes the first 'mock microinjection' on day 5 . ${ }^{*} p<0.05$ vs. ethanol intake on days 3 and 4 ; ${ }^{*} p<0.05$ vs. activity on days $1-4$. 
A

Microinjection Test Ethanol Consumption

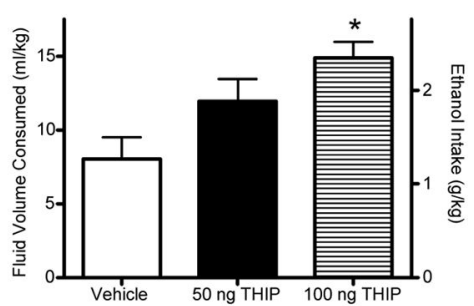

B

Blood Ethanol Concentration

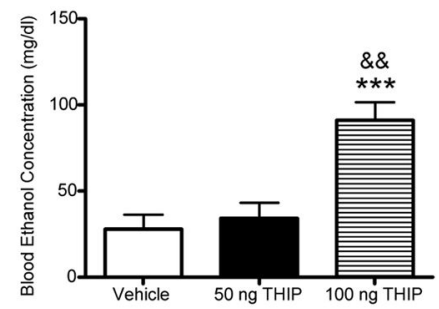

C Microinjection Test Locomotor Activity - Ethanol

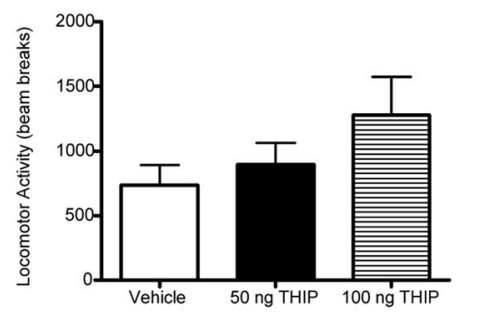

Figure 3. Microinjection test ethanol consumption parameters

A) Ethanol consumption on day 7 following bilateral microinfusion of saline vehicle $(n=9)$, $50 \mathrm{ng}(n=12)$, or $100 \mathrm{ng}(n=8)$ THIP into the ILC. B) BEC values calculated from blood samples taken immediately following DID on day 7. C) Locomotor activity during the 2-hr DID test. $* p<0.05,{ }^{*} * p<0.001$ vs. vehicle; ${ }^{*} \& p<.01$ vs. 50 ng THIP. 


\section{A $5 \%$ Sucrose Consumption}

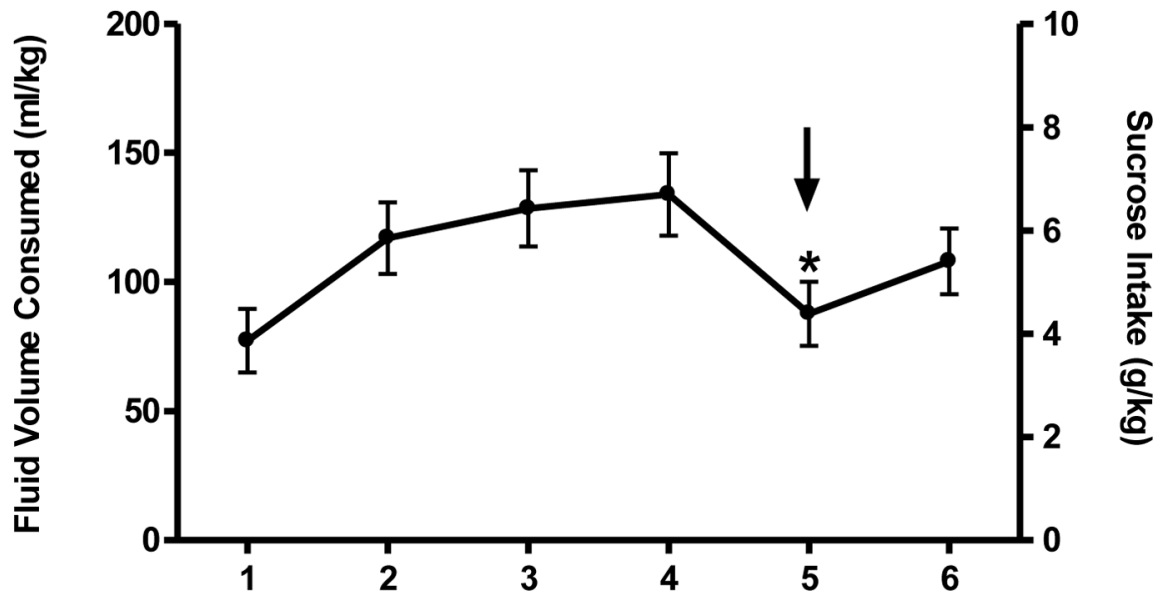

Day

B Home Cage Locomotor Activity - Sucrose

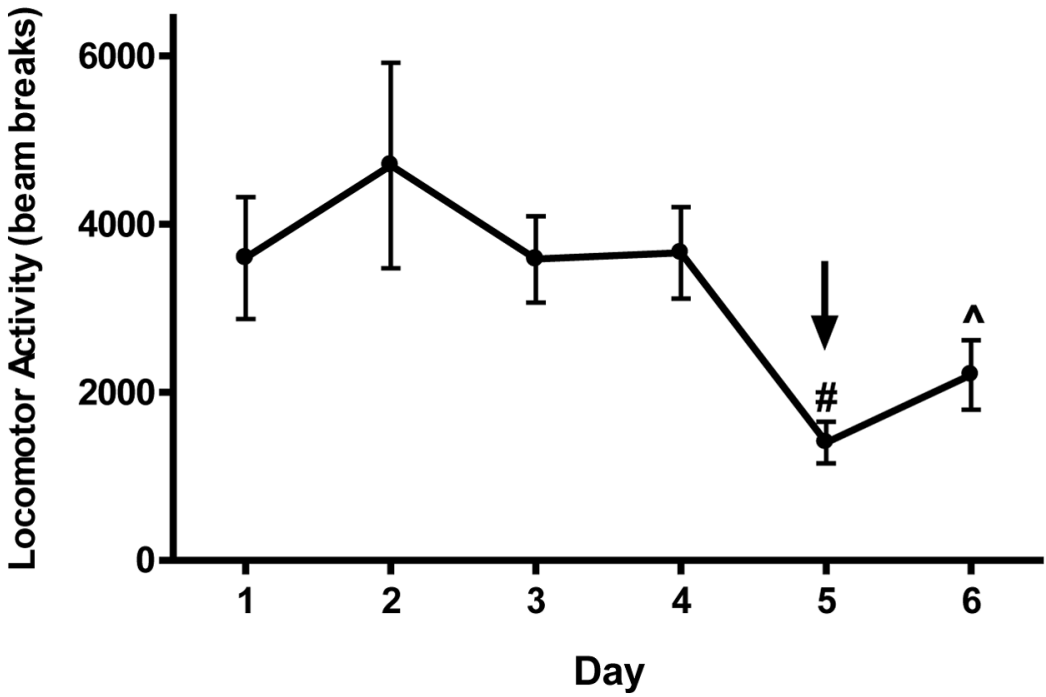

Figure 4. Acquisition of sucrose drinking

A) Consumption of $5 \%(\mathrm{w} / \mathrm{v})$ sucrose via DID and B) home cage locomotor activity across the 6 days of handling habituation. The data are presented collapsed on subsequent THIP dose group as there were no significant differences $(p>0.05)$ between groups in sucrose intake or activity across days $1-6(\mathrm{~N}=22)$. The arrow notes the first 'mock microinjection' on day 5 . ${ }^{*} p<.05$ vs. sucrose intake on days 3 and 4 ; ${ }^{*} p<0.05$ versus activity on days $1-4$; ${ }^{\wedge} p<0.05$ versus activity on days $2-3$ 
A Microinjection Test Sucrose Consumption

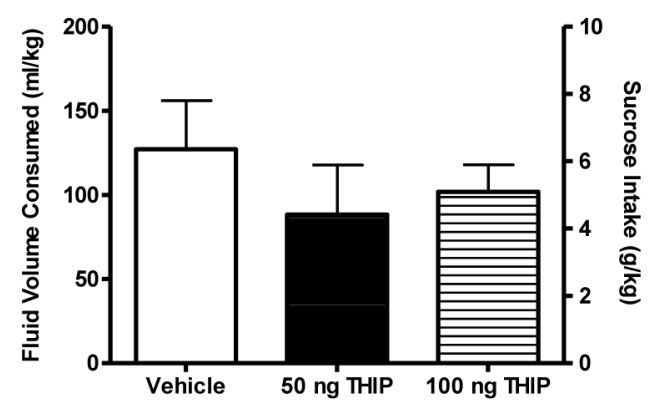

B

Microinjection Test Locomotor Activity - Sucrose

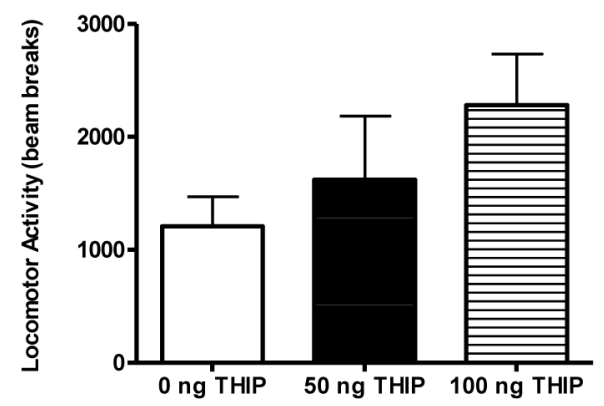

Figure 5. Microinjection test sucrose consumption parameters

A) Sucrose consumption on day 7 following bilateral microinfusion of saline vehicle $(n=6)$, $50 \mathrm{ng}(n=6)$, or $100 \mathrm{ng}(n=10)$ THIP into the ILC. B) Locomotor activity during the 2-hr DID test. 